\title{
Comparison of two DNA targets for the diagnosis of Toxoplasmosis by real-time PCR using fluorescence resonance energy transfer hybridization probes
}

\author{
Udo Reischl*1, Stéphane Bretagne ${ }^{2}$, Dominique Krüger ${ }^{3}$, Pauline Ernault ${ }^{4}$ \\ and Jean-Marc Costa ${ }^{4}$
}

\begin{abstract}
Address: ${ }^{1}$ Institute of Medical Microbiology and Hygiene, University Hospital Regensburg, Franz-Josef-Strauß-Allee 11, D-93053 Regensburg, Germany, ${ }^{2}$ Laboratoire de Parasitiologie, Hôpital H. Mondor-APHP and UMR BIPAR 946, F-94010 Créteil, France, ${ }^{3}$ Institute for Parasitology and Mycology, Robert-Koch Institut, Nordufer 20, D-13353 Berlin, Germany and ${ }^{4}$ Laboratoire de Biologie Moléculaire M Dassault, Hôpital américain de Paris, 63 Bd V. Hugo, BP 109, F-92202 Neuilly, France

Email: Udo Reischl* - udo.reischl@klinik.uni-regensburg.de; Stéphane Bretagne - bretagne@univ-paris12.fr;

Dominique Krüger - kruegerD@rki.de; Pauline Ernault - pauline.ernault@ahparis.org; Jean-Marc Costa - jean-marc.costa@ahparis.org

* Corresponding author
\end{abstract}

Published: 2 May 2003

BMC Infectious Diseases 2003, 3:7

This article is available from: http://www.biomedcentral.com/I47/-2334/3/7

(C) 2003 Reischl et al; licensee BioMed Central Ltd. This is an Open Access article: verbatim copying and redistribution of this article are permitted in all media for any purpose, provided this notice is preserved along with the article's original URL.
Received: 27 November 2002

Accepted: 2 May 2003

\begin{abstract}
Background: Toxoplasmosis is an infectious disease caused by the parasitic protozoan Toxoplasma gondii. It is endemic worldwide and, depending on the geographic location, 15 to $85 \%$ of the human population are asymptomatically infected. Routine diagnosis is based on serology. The parasite has emerged as a major opportunistic pathogen for immunocompromised patients, in whom it can cause life-threatening disease. Moreover, when a pregnant woman develops a primary Toxoplasma gondii infection, the parasite may be transmitted to the fetus and cause serious damnage. For these two subpopulations, a rapid and accurate diagnosis is required to initiate treatment. Serological diagnosis of active infection is unreliable because reactivation is not always accompanied by changes in antibody levels, and the presence of IgM does not necessarily indicate recent infection. Application of quantitative PCR has evolved as a sensitive, specific, and rapid method for the detection of Toxoplasma gondii DNA in amniotic fluid, blood, tissue samples, and cerebrospinal fluid.
\end{abstract}

Methods: Two separate, real-time fluorescence PCR assays were designed and evaluated with clinical samples. The first, targeting the 35 -fold repeated $\mathrm{BI}$ gene, and a second, targeting a newly described multicopy genomic fragment of Toxoplasma gondii. Amplicons of different intragenic copies were analyzed for sequence heterogeneity.

Results: Comparative LightCycler experiments were conducted with a dilution series of Toxoplasma gondii genomic DNA, 5 reference strains, and 5 I Toxoplasma gondii-positive amniotic fluid samples revealing a 10 to 100 -fold higher sensitivity for the PCR assay targeting the newly described 529-bp repeat element of Toxoplasma gondii.

Conclusion: We have developed a quantitative LightCycler PCR protocol which offer rapid cycling with real-time, sequence-specific detection of amplicons. Results of quantitative PCR demonstrate that the 529-bp repeat element is repeated more than 300 -fold in the genome of Toxoplasma gondii. Since individual intragenic copies of the target are conserved on sequence level, the high copy number leads to an ultimate level of analytical sensitivity in routine practice. This 
newly described 529-bp repeat element should be preferred to less repeated or more divergent target sequences in order to improve the sensitivity of PCR tests for the diagnosis of toxoplasmosis.

\section{Background}

Toxoplasmosis is an infectious disease caused by the protozoan Toxoplasma gondii effecting individuals throughout the world. Two main subpopulations are highly susceptible to this parasite: the fetus and an immunocompromised individual. Congenital infection may induce spontaneous abortion or serious sequelae when maternal infection occurs during pregnancy. Both the damage for the fetus (the sooner, the more deleterious) and the frequency of trans-placental transmission (the later, the more frequent) is usually depending on the stage of gestation. In the immunocompromised host, the prognosis for cerebral disseminated toxoplasmosis is poor, with a mortality rate of $63 \%$ [1]. For these two subpopulations, a rapid and accurate diagnosis is required to initiate treatment. Diagnosis with radiological findings, histology, tissue culture, or inoculation into mice is difficult, time consuming, or impractical. Since anti-toxoplasma antibody titers are often unchanged or decreased at the onset of clinical symptoms, and most cases of active toxoplasmosis are due to reactivation of latent infection, the serological status is solely useful in order to know whether the patient is at risk for reactivation. This is why the direct demonstration of the parasite in tissues or other biological fluids by PCR is a major breakthrough for the diagnosis of toxoplasmosis in these patients $[2,3]$.

The reliability of the detection of $T$. gondii DNA in amniotic fluids (AF) or blood is of utmost importance. Realtime PCR assays have recently emerged as a dramatic improvement in the reliability of PCR assays. Since the reaction tubes need not be opened after amplification, avoiding potential contamination of the environment with amplicons, the risk of false positive results are dramatically reduced. Quantitative PCR also provides additional data to direct the choice of specific treatments [4].

Real-time PCR also provides the opportunity to compare the sensitivity of different DNA targets. Several studies report a relatively high level of false negative results in prenatal diagnosis [5] or huge differences between immunocompromised patients using current PCR assays $[6,7]$. This may be due to pathophysiological reasons, explaining the absence or intermittent presence of the parasite in the specimens tested, or by poor performance of the PCR assays. The use of more repetitive but not polymorphic DNA targets may help to resolve this issue.
We have developed a real-time PCR assay targeting a recently discovered repetitive 529-bp DNA fragment in $T$. gondii [8], and compared the results to our previously developed PCR assay targeted to the multicopy gene B1 [9]. Whereas the number of $\mathrm{B} 1$ gene copies has been estimated around 35, the number of repeats of the 529-bp DNA fragment is reported to be between 230 and 330 [8]. We compared the sensitivity our two LightCycler (LC) PCR assays with serial dilutions of T. gondii DNA and subsequently analyzed amniotic fluids to compare the efficiency of the two PCR protocols.

\section{Methods}

\section{T. gondii isolates, clinical samples and bacterial strains}

Five reference strains of $T$. gondii, including the RH strain, two of zymodeme 1, two of zymodeme 2, one of zymodeme 3 [10], and seven strains derived from human amniotic fluids (AF), were selected from the culture collections of our institutions. DNA preparations from 51 amniotic fluid samples, which were received by the Hôpital américain de Paris between 1996 to 2001 and tested T. gondii positive using a previously published PCR assay [11], were used as PCR templates. In addition, 160 clinical specimens of various types originating from patients without a suspected T. gondii infection (about $50 \%$ of these patients were seropositive for Toxoplasma but do not show clinical symptoms of acute disease), and 118 strains from different bacterial genera, were included in the study.

\section{Template DNA preparation}

Genomic DNA of $T$. gondii strains was prepared as desribed previously [11]. Template DNA from clinical specimens was prepared using the High Pure PCR Template Preparation kit (Roche Diagnostics, Mannheim, Germany) according to the manufacturer's instructions. Following the centrifugation and washing steps, total DNA was eluted from the spin columns with $100 \mu$ l of elution buffer, and $5 \mu$ aliquots were directly transferred to a PCR reaction.

\section{Nucleotide sequence analysis of the cryptic T. gondii tar- get}

To identify potential sequence variations within the target sequence among different $T$. gondii strains, or among different copies of the gene within the chromosome of one organism, total genomic DNA of 5 reference strains and 7 clinical isolates were amplified using primer Tox-8 (5'CCC AGC TGC GTC TGT CGG GAT-3') and primer Tox-5 (5'-GAC GTC TGT GTC ACG TAG ACC TAA G-3'). Specific 
Table I: Oligonucleotide primers and LightCycler hybridization probes used in the PCR assay.

\begin{tabular}{|c|c|c|c|c|c|}
\hline Oligo-nucleotide & Sequence $^{\mathbf{a}}$ & Target gene & $\begin{array}{l}\text { Nucleotide } \\
\text { position }\end{array}$ & $\begin{array}{c}\text { GenBank } \\
\text { accession no. }\end{array}$ & Reference \\
\hline Tox-9 & AGG AGA GAT ATC AGG ACT GTA G & Cryptic & $143-164$ & AF487550 & Present study \\
\hline Tox-II & GCG TCG TCT CGT CTA GAT CG & Cryptic & $304-285$ & AF487550 & Present study \\
\hline Tox-HP-I & GAG TCG GAG AGG GAG AAG ATG TT-[FL] & Cryptic & $214-236$ & AF487550 & Present study \\
\hline Tox-HP-2 & [Red 640]-CCG GCT TGG CTG CTT TTC CTG-Ph & Cryptic & $238-258$ & AF487550 & Present study \\
\hline
\end{tabular}

a [FL], fluorescein; [Red 640], LightCycler-Red 640-N-hydroxy-succinimide ester; [Ph], 3'-phosphate.

amplification products of 450-bp were purified using the HighPure PCR Product Purification kit (Roche Diagnostics), and cycle sequencing reactions were performed as described in the PRISM Ready Reaction Dye Deoxy Terminator cycle sequencing kit protocol (Applied Biosystems, Weiterstadt, Gemany). Both strands of amplicons originating from different amplification reactions were sequenced in duplicate to rule out the possibility of Taq DNA polymerase-induced errors. Optimal results were obtained using amplification primers Tox- 8 and Tox- 5 as forward and reverse sequencing primers, respectively. The fluorescent-labeled reaction products were analyzed with a ABI PRISM 310 Genetic Analyzer (Applied Biosystems).

\section{Primer and hybridization probe design}

One LC-PCR assay, which was described in detail previously, targeted the B1 gene of T. gondii $[4,11]$. The other LC-PCR assay targeted a recently described T. gondii 529bp DNA repeat element of cryptic function. Based on the newly determined consensus sequence GenBank AF487550, two primer oligonucleotides were selected flanking a conserved 162-bp region within the T. gondiispecific repeat element. For the sequence-specific detection of the corresponding amplicons, a pair of LightCycler hybridization probes were designed against sequences internal to the amplified region. The nucleotide sequences of primers and hybridization probes and their corresponding locations within GenBank AF487550 are shown in Table 1.

\section{LC-PCR assays and product detection}

DNA oligonucleotide primers and hybridization probes were synthesized by TIB Molbiol, Berlin, Germany. All LCPCR assays were performed using a fluorescence detecting temperature cycler (LightCycler; Roche Diagnostics). The amplification mixture consisted of $2 \mu \mathrm{l}$ of $10 \mathrm{X}$ reaction mix (LightCycler FastStart Master Hybridization Probes, Roche Diagnostics), $4 \mathrm{mM} \mathrm{MgCl} 2,0.5 \mu \mathrm{M}$ of each oligonucleotide primer, $0.25 \mu \mathrm{M}$ of each oligonucleotide probe, and $5 \mu \mathrm{l}$ of template DNA in a final volume of 20 $\mu \mathrm{l}$. Carry-over was prevented by using the heat-labile uracyl-DNA-glycosylase (UNG) (Roche Diagnostics). The reaction mixture was initially incubated for $1 \mathrm{~min}$ at room temperature to allow the UNG to act. This incubation was followed by a 10 -min incubation step at $95^{\circ} \mathrm{C}$ to denature the template DNA, to inactivate the UNG enzyme, and to activate the Fast Start Taq DNA polymerase. Samples were amplified as follows: 50 cycles of denaturation at $95^{\circ} \mathrm{C}$ for $10 \mathrm{sec}$, annealing at $56^{\circ} \mathrm{C}$ for $20 \mathrm{sec}$, and an extension at $72^{\circ} \mathrm{C}$ for 20 sec. The temperature transition rate was $20^{\circ} \mathrm{C} / \mathrm{sec}$.

The generation of target amplicons for each sample was monitored between the annealing and the elongation steps at $640 \mathrm{~nm}$. Samples positive for target genes were identified by the instrument at the cycle number where the fluorescence attributable to the target sequences exceeded that measured for background. Those scored as positive by the instrument were confirmed by visual inspection of the graphical plot (cycle number versus fluorescence value) generated by the instrument.

\section{Quantification of LightCycler products}

The quantitative interpretation of LightCycler results was assisted by the "fit point method" algorithm with the "minimize error" option (LightCycler software Vers. 3.5; Roche Diagnostics). The LightCycler software performs all additional calculation steps necessary for generation of a standard curve. Briefly, a noise band (treshold) is automatically set at a fluorescence level, at which the fluorescence signal development reflects that the PCR is in the log-linear phase. The software then calculates the logarithmic values by interpolating a straight line through 2 data points above the treshold value, and the points of intersection (crossing points) with the noise band are determined. Finally, the crossing points are plotted against the logarithm of the target DNA concentration in individual samples.

\section{Sensitivity of the LC-PCR assays for T. gondii detection}

To assess the the analytical sensitivity of the PCR assays for the two different target genes, 10-fold serial dilutions of $T$. gondii DNA (RH strain) were prepared, ranging from $2 \mathrm{ng}$ to $2 \mathrm{fg}$ input per $20 \mu \mathrm{l}$ PCR reaction. On the assumption that one $80-\mathrm{Mbp}$ genome equivalent of $T$. gondii equals about $80 \mathrm{fg}$, this would be $2.5 \times 10^{4}$ down to $2.5 \times 10^{-2}$ 
parasite equivalents. The dilution series were tested in triplicate with the two LC-PCR assays to determine the minimum amount of template DNA per reaction that could be detected by each protocol.

\section{Results}

\section{Sequencing of $\mathrm{T}$. gondii reference strains}

Sequencing plots obtained with the amplicons originating from the five reference strains and the seven clinical isolates of $T$. gondii were clearly interpretable. An alignment of the 404-bp region flanked by primers Tox- 8 and Tox-5 showed complete homology between the nucleotide sequences among the investigated strains. Compared to GenBank AF146527, some divergent nucleotide positions were observed. Briefly, an "A" to "G" substitution was identified at pos. 160, a "C" to "T" substitution at pos. 391, and a "G" to "C" substitution at pos. 495. An ambiguous "S" nucleotide position was consistently observed at pos. 275, which indicated the presence of either " $G$ " or "C" nucleotides within different copies of the 529-bp fragment in the genome of T. gondii. At pos. 367 the deletion of an "A" nucleotide was consistently observed with all sequenced isolates of $T$. gondii. The nucleotide sequence of the newly determined 404-bp partial sequence within the T. gondii 529-bp repeat region was deposited in GenBank under accession number AF487550.

Direct sequencing of amplicons generated with $51 \mathrm{~T}$. gondii-positive human amniotic fluid samples revealed complete homology to the newly determined GenBank AF487550, and all of the variant nucleotide positions with respect to GenBank AF146527 were confirmed.

\section{Comparison of analytical sensitivity for the two targets}

When the B1-specific set of LightCycler PCR primers and hybridization probes were applied to the 10-fold dilution series of T. gondii genomic DNA, a detection limit of 200 fg was consistently observed after 35 cycles of amplification. As expected, this level of analytical sensitivity was in agreement with previous reports $[4,11]$.

When the set of LightCycler PCR primers and hybridization probes specific for the $T$. gondii 529-bp repeat element was applied to an identical dilution series of template DNA, a detection limit of about $20 \mathrm{fg}$ of T. gondii genomic DNA was consistently observed after 35 cycles of amplification. Graphs depicting the accumulation of fluorescence throughout the PCR assays for the B1 gene and the 529-bp repeat element with 10 -fold dilution series of genomic DNA are shown in Figures 1 and 2.

For a given starting concentration of template DNA present in individual reaction mixtures, the quantitative PCR results expressed in crossing points (Cp) were about 3.5 cycles earlier with the 529-bp repeat element LC assay than with the B1 gene LC assay. From the slope of the calculated standard curve, the efficiency of the underlying amplification process (10-1/slope) was calcultated as 1.84 for both the B1 gene (Figure 1) and the 529-bp repeat element (Figure 2). This value was near to the theoretical optimum of 2, and indicated an optimal course of the amplification process leading to precise and reproducible quantitative results. Based on the principle of quantitative PCR, $\mathrm{N}=\mathrm{N}_{0} \times \mathrm{E}^{\mathrm{n}}$ (where $\mathrm{N}$ is the actual number of amplicons present in the reaction mixture after $n$ cycles, $N_{0}$ is the initial number of template molecules, and $\mathrm{E}$ is the efficiency of the amplification process), a difference of 3.5 crossing points for a given starting concentration of template DNA equals a tenfold higher concentration of amplicons in the reaction mixture for the 529-bp repeat element during the logarithmic phase of amplification. Considering the identical amplification efficiencies observed for both LC protocols, it was a clear indication that the actual number of 529-bp repeat elements within the genome of T. gondii is at least tenfold higher than the 35fold repeated $\mathrm{B} 1$ gene. Comparative $\mathrm{LC}$ experiments on a collection of $51 \mathrm{~T}$. gondii-positive human amniotic fluids showed a gain in Cp of $4.6+/-1.1$ cycles (range 2.4-6.9) for the assay targeting the 529-bp repeat element (Figure 3 ). These results obtained with clinical specimens were in agreement with the above mentioned findings on the dilution series of T. gondii genomic DNA.

\section{Specificity of the LC assays}

The specificity of the LC assay targeting the $\mathrm{B} 1$ gene of $T$. gondii has been investigated before $[4,11]$. The analytical specificity of the LC assay targeting the 529-bp-repeat element was evaluated by testing DNA preparations from 5 reference strains and 7 clinical strains of $T$. gondii. In addition, DNA preparations from $51 \mathrm{~T}$. gondii-positive amniotic fluids, $160 \mathrm{~T}$. gondii-negative clinical specimens, and 118 strains of diverse clinically relevant bacterial species were included in the study. With all of the $62 \mathrm{~T}$. gondiipositive DNA preparations, clearly positve results were obtained from the LightCycler amplification screen and a specific $\mathrm{T}_{\mathrm{m}}$ of $65^{\circ} \mathrm{C}$ was consistently observed upon melting curve analysis. DNA preparations from 160 clinical specimens, originating from patients without a suspected T. gondii infection, as well as from 118 strains of different bacterial genera, remained negative from the LightCycler amplification screen and in melting curve analysis. No cross-reactions or borderline results from high amounts of human chromosomal DNA were observed. The specificity, and the predictive value of the LC-PCR assay targeting the 529-bp repeat element were each $100 \%$.

\section{Discussion}

As for all parasitic diseases, the PCR diagnosis of toxoplasmosis is not standardized. It seems highly probable that there will be a consensus on real-time PCR assays in the 

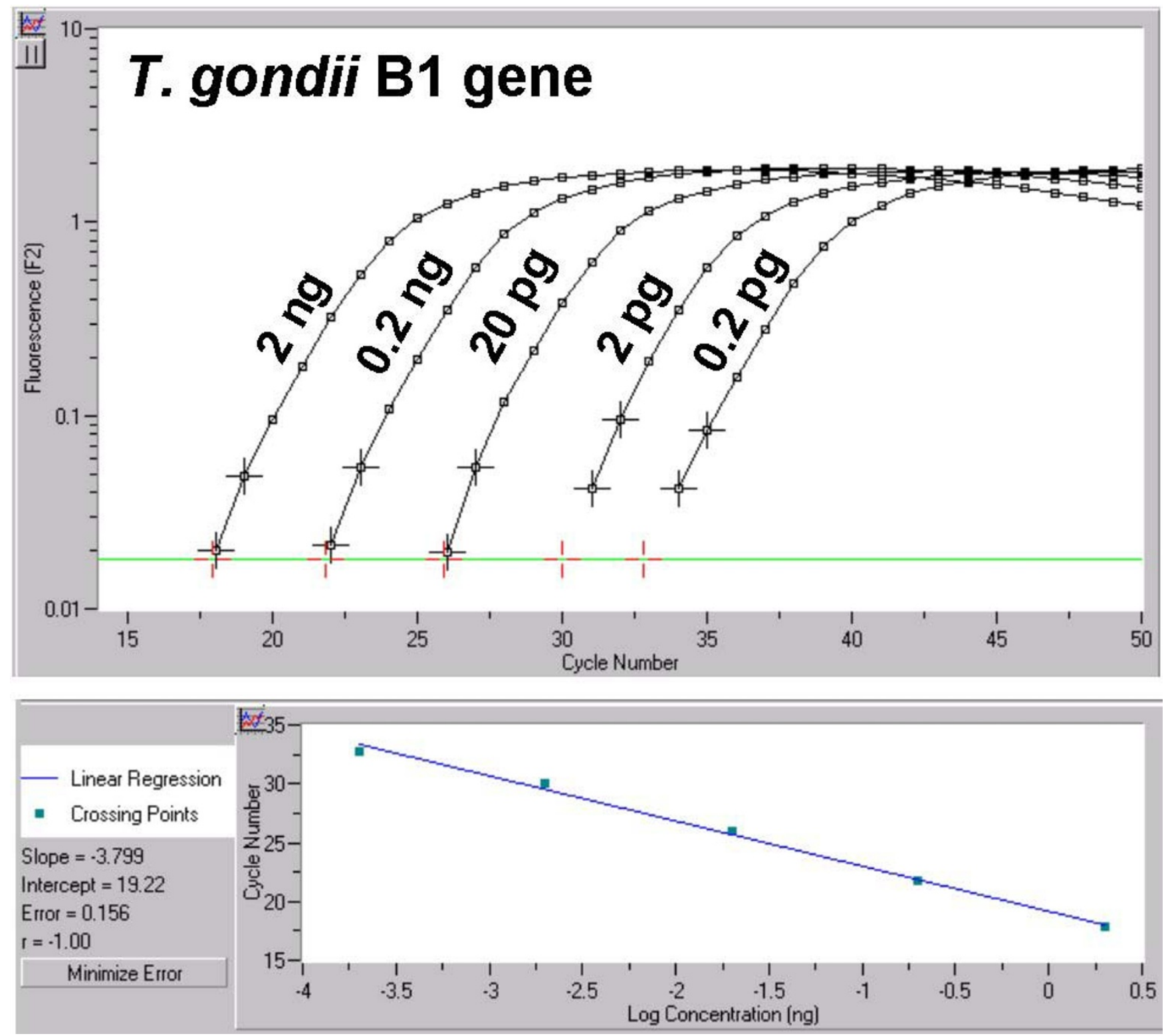

\section{Figure I}

Quantitative analysis of LightCycler results obtained on I0-fold serial dilutions of $T$. gondii genomic DNA using the B I-specific PCR protocol. The corresponding template DNA concentrations, ranging from $2 \mathrm{ng}$ to $0.2 \mathrm{pg}$ input per 20 $\mu \mathrm{I}$ PCR reaction, are indicated next to the amplicon curves. Based on the slope of the original amplification curves during the log-linear phase determined by two data points, artificial crossing points with the noise band (horizontal line) were determined by the LightCycler software $(A)$. The standard curve represented the linear regression line through the data points on a plot of crossing points (threshold cycle) vs logarithm of standard sample concentration (B). Slope, Y-intercept, mean squared error, and regression coefficient of the standard curve are given.

next few years $[4,11,12]$. However, the consensus on the best sequence to be amplified will be more difficult. The findings of our study clearly confirm that the recently described 529-bp DNA fragment is present in much higher copy number than the 35 -fold repeated $\mathrm{B} 1$ gene [8], and is highly conserved on a nucleotide sequence level between strains and isolates. Therefore, this DNA target offers an improvement in the sensitivity of PCR tests for the detection of $T$. gondii DNA. 

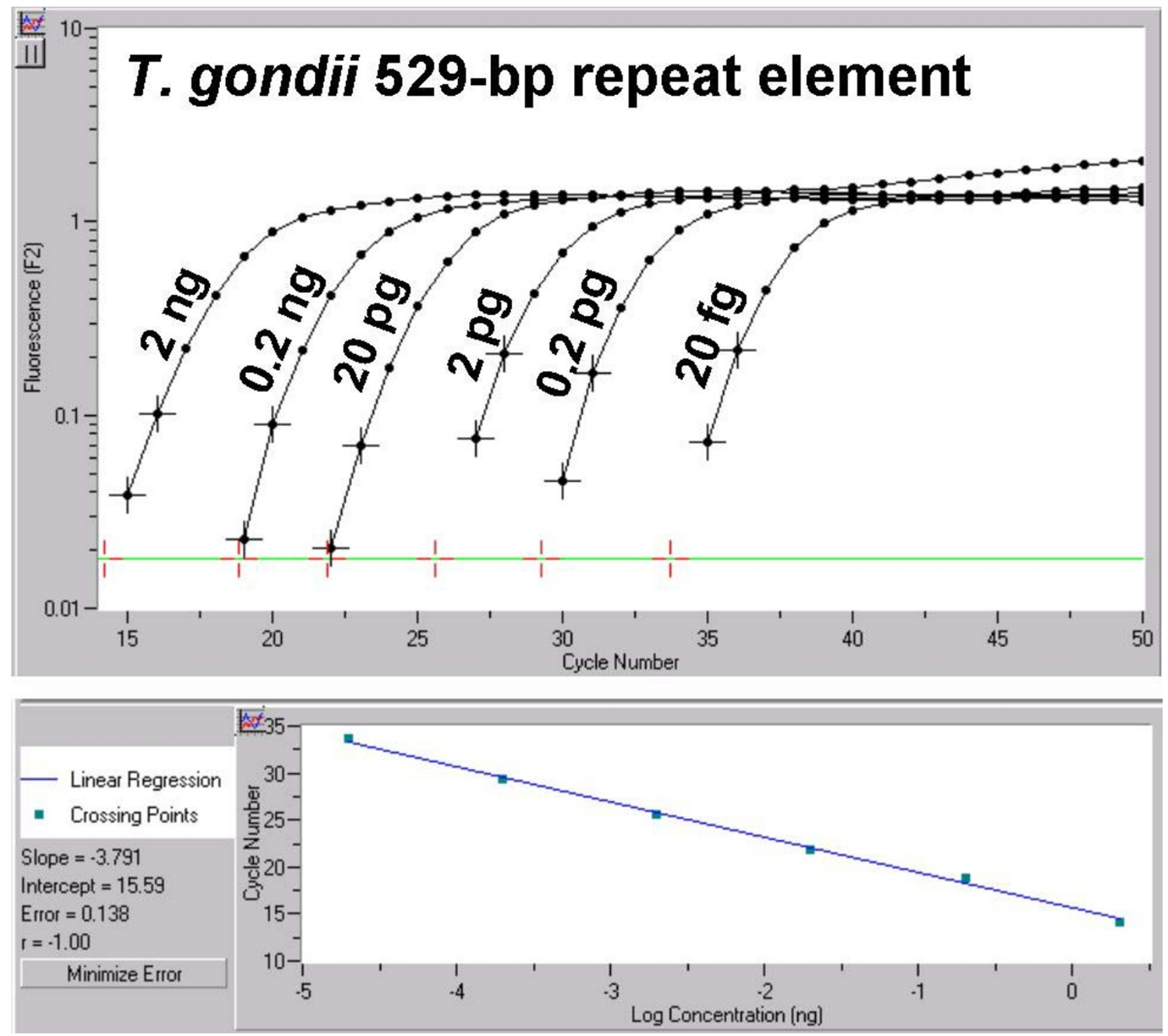

\section{Figure 2}

Quantitative analysis of LightCycler results obtained on I 0-fold serial dilutions of T. gondii genomic DNA using the PCR protocol specific for the 529-bp repeat element. The corresponding template DNA concentrations, ranging from $2 \mathrm{ng}$ to $20 \mathrm{fg}$ input per $20 \mu \mathrm{l}$ PCR reaction, are indicated next to the amplicon curves. Based on the slope of the original amplification curves during the log-linear phase determined by two data points, artificial crossing points with the noise band (horizontal line) were determined by the LightCycler software $(A)$. The standard curve represented the linear regression line through the data points on a plot of crossing points (threshold cycle) vs logarithm of standard sample concentration (B). Slope, $Y$-intercept, mean squared error, and regression coefficient of the standard curve are given.

Three repeated DNA sequences have been studied so far for the diagnosis of toxoplasmosis. The rRNA genes have been the basis for several independent PCR assays $[6,13,14]$ but the homogeneity of the amplified fragments has never been demonstrated to a sufficient extent. That may explain the observation of Jones et al. [15], who found the 35-fold repeated B1 target more sensitive than the ribosomal genes [14]. The TGR $1_{\mathrm{E}}$ is a non-coding repetitive element of $T$. gondii, evaluated as a diagnostic target for PCR $[16,17]$, but abandoned because of sequence 


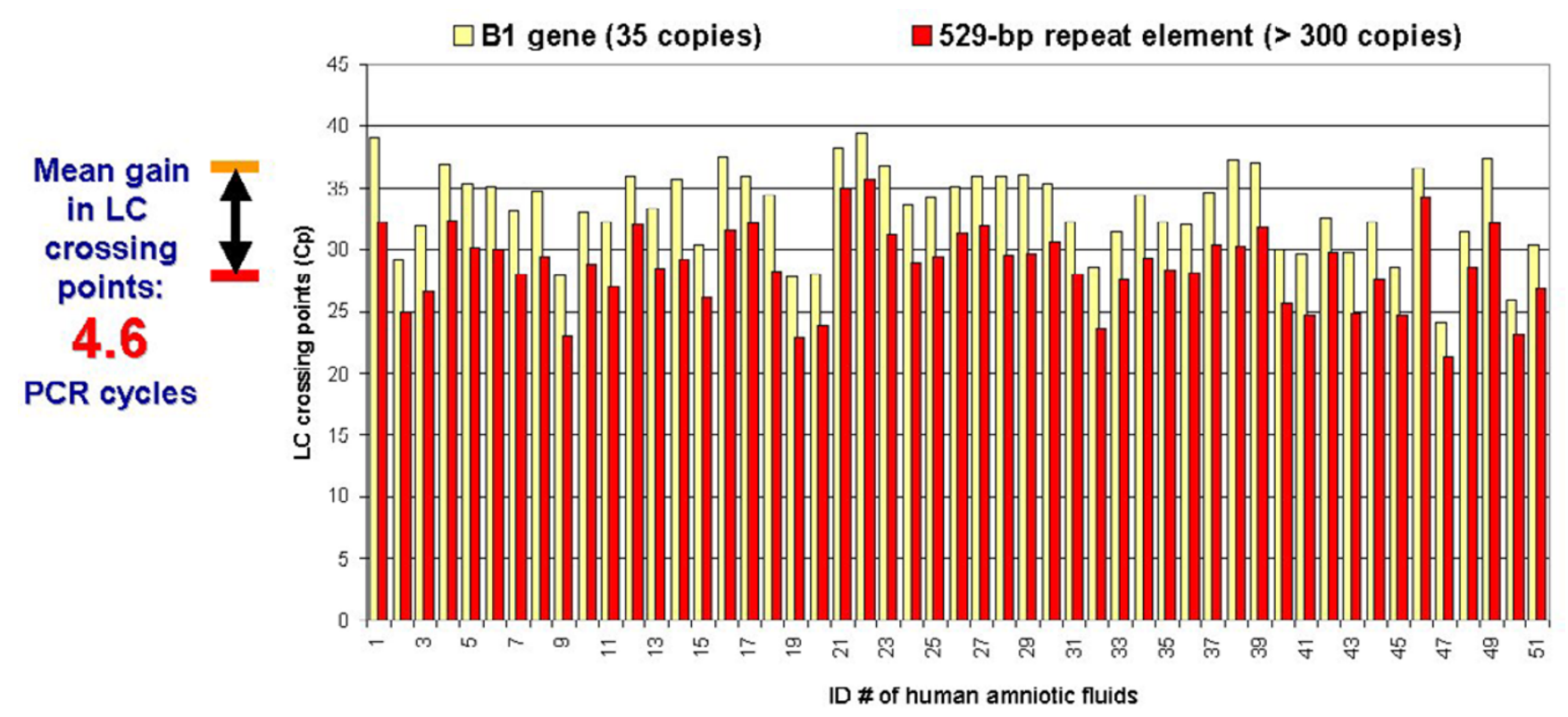

\section{Figure 3}

Results of LightCycler experiments on 5 I T. gondii-positive human amniotic fluids comparing the B I-specific PCR protocol and the PCR protocol specific for the 529-bp repeat element. Comparative LC PCR experiments were performed on DNA preparations of a collection of $5 \mathrm{I}$ T. gondii-positive human amniotic fluids. The real-time PCR assay targeting the 529-bp repeat element (red bars) showed a mean gain in LC crossing points of 4.6 with respect to the real-time PCR assay targeting the BI gene (yellow bars). The diagram depicts the individual LC crossing points ( $x$-axis) observed for each of the investigated amniotic fluid samples (y-axis).

heterogeneity among different copies of the repeated elements and the impossibility to find suitable PCR primers for amplification [18]. Up till now, the most popular DNA target for diagnosing toxoplasmosis was the B1 gene, with a huge diversity of published primers and PCR protocols $[3,6,11,19-22]$. Altough the heterogeneity of the B1 repeats is well known [23], it seems to be sufficiently conserved for diagnostic purposes. However, the primers for amplification must be carefully designed to amplify all the different types of $T$. gondii. We have shown that most of the T. gondii isolates in amniotic fluids are of type 2 [24], whereas most of the published PCR primers are designed complementary to the type 1 sequences.

With respect to the recently described 529-bp repeat element, the sequencing data indicate a highly conserved nucleotide sequence among various strains and isolates of $T$. gondii and, equally important for hybridization probebased detection of amplicons, among different intragenomic copies of this particular target. Alignment of our sequencing results with 62 different $T$. gondii isolates (5 reference strains, 7 clinical isolates and $51 \mathrm{~T}$. gondii-positive amniotic fluids) revealed 3 nucleotide mutations, one deletion, and one defined nucleotide ambiguity com- pared to GenBank AF146527. The newly determined 404bp partial sequence within the T. gondii 529-bp repeat region was deposited as GenBank AF487550.

Since the sequence of the original GenBank entry AF146527 was obtained with cloned amplicons, only single molecules of the 529-bp amplicons have been investigated by Homan et al. [8]. Without doubt, this project was an important step towards the molecular characterization of the T. gondii-specific 529-bp repeat element. Knowing about, and, as a consequence, omitting the extremely "T"rich region at the 3' end of the target gene, we used the primer pair Tox- 5 and Tox- 8 for amplification and direct sequencing of a 404-bp internal segment. This integrated sequencing approach, in connection with the $\mathrm{ABI}$ fourdye one-lane sequencing technology, led to a more detailed insight into the nucleotide variations present at individual positions within different intragenomic copies of the T. gondii 529-bp repeat element.

Based on the newly determined consensus sequence GenBank AF487550, we designed a set of LightCycler PCR primers and hybridization probes specific for the $T$. gondii 529-bp repeat element. Compared to a well-established 
LC protocol targeting the $\mathrm{B} 1$ gene, the analytical sensitivity of the novel LC protocol was evaluated with 10-fold dilution series of $T$. gondii genomic DNA. Here a detection limit of 20 fg of genomic DNA was consistently observed, which was found to be ten times more sensitive than the results obtained with the B1-specific LC assay.

Real-time PCR provides quantitative results, since the cycle number in which amplicons become detectable is proportional to the logarithm of initial number of templates. Identical amplification efficiencies and the fact that a gain in crossing point values of about 3.5 cycles was observed with the 529-bp repeat element LC assay for a given starting concentration of template DNA, the actual copy number of 529-bp repeat elements within the genome of T. gondii must be at least tenfold higher than the copy number of the 35-fold repeated B1 gene. Statistical exploitation of quantitative LightCycler results obtained with 51 T. gondii-positive human amniotic fluids showed a gain in crossing point values of 4.6 in average, thereby supporting the practical advantage of the 529-bp repeat element over the $\mathrm{B} 1$ gene as diagnostic target with respect to assay sensitivity.

With respect to the quantitative PCR protocol of Homan et al. [8], who amplified the complete 529-bp repeat region and observed a detection limit of four tachyocytes, we intentionally amplified only an internal 162-bp segment of the target gene, thereby omitting the extremely "T"-rich region at the 3 '-end. It is well known that long stretches of identical nucleotides in the template strand may cause a "stuttering" behaviour of the Taq DNA polymerase reducing the speed of the elongation process or causing the enzme to fall off the template strand. Leaving this problematic " $\mathrm{T}$ "-rich segment of the target gene improved the efficiency of the amplification process and a detection limit of less than one tachyzoite equivalent was observed in the present study.

The specificity of the newly developed LC assay targeting the the $T$. gondii 529-bp repeat element was evaluated with DNA preparations of $62 T$. gondii isolates or clinical specimens positive for $T$. gondii, 160 clinical specimens from patients without a suspected $T$. gondii infection, and 118 strains of different bacterial species. Positive PCR results were observed with only the $62 \mathrm{~T}$. gondii-positive DNA preparations whereas all of the other DNA preparations remained negative. No cross-reactions or borderline PCR results in the presence of high amounts of human chromosomal DNA were observed. Consistently negative PCR results were observed with specimens of various types originating from individuals who had anti-toxoplasma antibodies but no clinical symptoms of acute toxoplasmosis.
Although we evaluated the novel LC assay with a collection of T. gondii-positive amniotic fluid samples, other biological fluids like blood, aqueous humor, vitreous, or tissues may also serve as starting material for the sensitive detection of the parasites in clinical samples [25,26]. It should be considered that the repartition of the toxoplasmosis cysts in organs, such as heart or brain, is not homogenous and the size of the sample subjected to DNA extraction is a key issue. Consequently, a negative PCR result with a small biopsy section does not definitively exclude the presence of toxoplasmosis cysts in a given organ or clinical sample.

\section{Conclusions}

We have developed a quantitative $T$. gondii-specific LightCycler protocol which offer rapid cycling (1 hour or less) with real-time, sequence-specific detection of amplicons. The fluorescent-labeled hybridization probes not only provide confidence in the identification of the target sequence, but also reduce the risk of experiencing product contamination of the laboratory since the amplification reaction and the detection of PCR products are conducted in a single capillary tube. From quantitative PCR it can be concluded that the 529-bp repeat element of T. gondii [8] is repeated more than 300-fold. Sequencing of PCR amplicons demonstrated a highly conserved nature of individual intragenic copies of this multicopy gene. No significant sequence homologies with other GenBank entries were observed. This newly described target sequence should be preferred to less repeated or more divergent target sequences in order to improve the sensitivity of the PCR tests for the diagnosis of toxoplasmosis.

\section{Competing interests}

None declared.

\section{Authors' contributions}

U. Reischl, S. Bretagne and J.-M. Costa were responsible for the development, probe design, and evaluation of the novel PCR assay. P. Ernault was involved in testing DNA preparations of human amniotic fluids. Last but not least, D. Krüger made his colleagues aware of this novel T. gondii-specific target sequence.

\section{Acknowledgements}

We acknowledge Jeffrey Emch for critical review of the manuscript.

\section{References}

I. Martino R, Maertens J, Bretagne S, Rovira M, Deconinck E, Ullmann AJ, Held $T$ and Cordonnier C Toxoplasmosis after hematopoietic stem cell transplantation Clin Infect Dis 2000, 3 I: I I88-II 95

2. Bretagne S, Costa JM, Vidaud M, Tran J, Nhieu V and Fleury-Feith J Detection of Toxoplasma gondii by competitive DNA amplification of bronchoalveolar lavage samples J Infect Dis 1993, 168:1585-1588

3. Hohlfeld P, Daffos F, Costa JM, Thulliez P, Forestier F and Vidaud M Prenatal diagnosis of congenital toxoplasmosis with a 
polymerase-chain-reaction test on amniotic fluid New Engl J Med 1994, 33 I:695-699

4. Costa JM, Pautas C, Ernault P, Foulet F, Cordonnier $C$ and Bretagne $S$ Real-time PCR for diagnosis and follow-up of Toxoplasma reactivation after allogeneic stem cell transplantation using fluorescence resonance energy transfer hybridization probes / Clin Microbiol 2000, 38:2929-2932

5. Romand S, Wallon M, Franck J, Thulliez P, Peyron F and Dumon H Prenatal diagnosis using polymerase chain reaction on amniotic fluid for congenital toxoplasmosis Obstet Gynecol 200I, 97:296-300

6. Foudrinier F, Aubert D, Puygauthier-Toubas D, Rouger C, Beguinot I, Halbout P, Lemaire P, Marx-Chemla C and Pinon JM Detection of Toxoplasma gondii in immunodeficient subjects by gene amplification: influence of therapeutics Scand J Infect Dis 1996, 28:383-386

7. Khalifa K-S, Roth $A$, Roth $B$, Arasteh $K N$ and Janitschke $K$ Value of PCR for evaluating occurrence of parasitemia in immunocompromised patients with cerebral and extracerebral toxoplasmosis J Clin Microbiol 1994, 32:28I3-2819

8. Homan WL, Vercammen M, De Braekeleer J and Verschueren $\mathrm{H}$ Identification of a 200- to 300 -fold repetitive 529 bp DNA fragment in Toxoplasma gondii, and its use for diagnostic and quantitative PCR Int J Parasitol 2000, 30:69-75

9. Burg JL, Grover CM, Pouletty P and Boothroyd JC Direct and sensitive detection of a pathogenic protozoan, Toxoplasma gondii, by polymerase chain reaction J Clin Microbiol 1989, 27: 17871792

10. Dardé ML Biodiversity in Toxoplasma gondii In: Current topics in microbiology and immunology (Edited by: Gross U) Berlin, Springer-Press |996, 27-4]

II. Costa JM, Ernault P, Gautier E and Bretagne S Prenatal diagnosis of congenital toxoplasmosis by duplex real-time PCR using fluorescence resonance energy transfer hybridization probes Prenat Diagn 200I, 21:85-88

12. Kupferschmidt O, Krüger D, Held TK, Ellerbrok H, Siegert $W$ and Janitschke K Quantitative detection of Toxoplasma gondii DNA in human body fluids by TaqMan polymerase chain reaction Clin Microbiol Infect 200 I, 7:120-124

13. Dupon M, Cazenave J, Pellegrin JL, Ragnaud JM, Cheyrou A, Fischer I, Leng B and Lacut JY Detection of Toxoplasma gondii by PCR and tissue culture in cerebrospinal fluid and blood of human immunodeficiency virus-seropositive patients J Clin Microbiol I995, 33:242I-2426

14. Guay JM, Dubois D, Morency MJ, Gagnon S, Mercier J and Levesque RC Detection of the pathogenic parasite Toxoplasma gondii by specific amplification of ribosomal sequences using comultiplex polymerase chain reaction J Clin Microbiol I993, 3 I :203207

15. Jones $C D$, Okhravi $N$, Adamson $P$, Tasker $S$ and Lightman $S$ Comparison of PCR detection methods for $B I, P 30$, and 185 rDNA genes of $T$. gondii in aqueous humor Invest $O$ phthalmol $V$ is Sci 2000, 41:634-644

16. Cristina N, Derouin F, Pelloux H, Pierce R, Cesbron-Delauwn MF and Ambroise-Thomas $P$ Detection of Toxoplasma gondii by "Polymerase Chain Reaction" (PCR) technique in AIDS infected patients using the repetitive sequence TGRIE Pathol Biol (Paris) 1992, 40:52-55

17. Robert F, Ouatas T, Blanche P, Tourte-Schaefer C, Sicard D and Dupouy-Camet J Retrospective evaluation of the detection of Toxoplasma gondii by polymerase chain reaction in AIDS patients Presse Med 1996, 25:54I-545

18. Angel SO, Matrajt M, Margarit J, Nigro M, Illescas E, Pszenny V, Amendoeira MR, Guarnera E and Garberi JC Screening for active toxoplasmosis in patients by DNA hybridization with the ABGTg7 probe in blood samples J Clin Microbiol 1997, 35:591595

19. Jenum PA, Holberg-Petersen M, Melby KK and Stray-Pedersen B Diagnosis of congenital Toxoplasma gondii infection by polymerase chain reaction (PCR) on amniotic fluid samples. The Norwegian experience Apmis 1998, 106:680-686

20. Lin MH, Chen TC, Kuo TT, Tseng CC and Tseng CP Real-time PCR for quantitative detection of Toxoplasma gondii J Clin Microbiol 2000, 38:4|2|-4|25

21. Pelloux $H$, Weiss J, Simon J, Muet F, Fricker-Hidalgo $H$, GoullierFleuret $A$ and Ambroise-Thomas $P$ A new set of primers for the detection of Toxoplasma gondii in amniotic fluid using polymerase chain reaction FEMS Microbiol Lett 1996, I38: I I-I5

22. Pujol-Rique M., Derouin F, Garcia-Quintanilla A, Valls ME, Miro JM and Jimenez de Anta MT Design of a one-tube hemi-nested PCR for detection of Toxoplasma gondii and comparison of three DNA purification methods ] Med Microbiol 1999, 48:857-862

23. Grigg ME and Boothroyd JC Rapid identification of virulent type I strains of the protozoan pathogen Toxoplasma gondii by PCR-restriction fragment length polymorphism analysis at the B I gene J Clin Microbiol 200 I, 39:398-400

24. Costa JM, Darde ML, Assouline B, Vidaud M and Bretagne S Microsatellite in the beta-tubulin gene of Toxoplasma gondii as a new genetic marker for use in direct screening of amniotic fluids J Clin Microbiol 1997, 35:2542-2545

25. Bretagne S, Costa JM, Foulet F, Jabot-Lestang L, Baud-Camus F and Cordonnier $C$ Prospective study of toxoplasma reactivation by polymerase chain reaction in allogeneic stem-cell transplant recipients Transpl Infect Dis 2000, 2:127-I32

26. Bretagne S, Costa JM, Cosnes A, Authier FJ, Vidaud M and Gherardi RK Lack of Toxoplasma gondii DNA in muscles of patients with inflammatory myopathy and increased anti-toxoplasma antibodies Muscle Nerve 1994, 17:822-824

\section{Pre-publication history}

The pre-publication history for this paper can be accessed here:

http://www.biomedcentral.com/1471-2334/3/7/prepub

Publish with Bio Med Central and every scientist can read your work free of charge

"BioMed Central will be the most significant development for disseminating the results of biomedical research in our lifetime. "

Sir Paul Nurse, Cancer Research UK

Your research papers will be:

- available free of charge to the entire biomedical community

- peer reviewed and published immediately upon acceptance

- cited in PubMed and archived on PubMed Central

- yours - you keep the copyright 